\title{
Development of a Catalytic Hollow Fibre Membrane Micro-Reactor for High Purity $\mathrm{H}_{2}$ Production
}

\author{
M.A. Rahman ${ }^{1}$, F.R. García-García, M.D. Irfan Hatim, B.F.K. Kingsbury, K. Li ${ }^{*}$ \\ Department of Chemical Engineering and Chemical Technology, \\ Imperial College London, London SW7 2AZ, United Kingdom.
}

\begin{abstract}
This article describes development of a catalytic hollow fibre membrane micro-reactor (CHFMMR) for high purity $\mathrm{H}_{2}$ production. Asymmetric $\mathrm{Al}_{2} \mathrm{O}_{3}$ hollow fibres produced by a phase-inversion and sintering technique were employed as a single substrate for both coating of the Pd membrane and impregnation of the $30 \% \mathrm{CuO} / \mathrm{CeO}_{2}$ catalyst. The Pd membrane was first deposited onto the outer layer of $\mathrm{Al}_{2} \mathrm{O}_{3}$ hollow fibre using the electroless plating (ELP) technique, followed by impregnation of the $30 \% \mathrm{CuO} / \mathrm{CeO}_{2}$ catalyst into the inner finger-like structure of the substrate using the sol-gel Pechini method. Performance of the proposed reactor was carried out using water gas shift (WGS) reaction as a sample reaction. A comparative study of conversion obtained in the WGS reaction as a function of the reaction temperature (from $200^{\circ} \mathrm{C}$ to $500^{\circ} \mathrm{C}$ ) in a fixed-bed reactor, a catalytic hollow fibre micro-reactor (CHFMR) and the CHFMMR using different flow rates of a sweep gas (from 45 to $70 \mathrm{ml} / \mathrm{min}$ ) was performed, concluding that the conversion is the highest in the CHFMMR. It is important to highlight that, at $500^{\circ} \mathrm{C}$ and a sweep gas flow rate of
\end{abstract}

\footnotetext{
* To whom correspondence should be addressed:

Tel: 44 (0) 207-5945676. Fax. 44 (0) 207-5945629. E-mail address:

kang.li@imperial.ac.uk

${ }^{1}$ Current address: Advanced Membrane Technology Research Centre (AMTEC), Faculty of Petroleum and Renewable Energy Engineering, Universiti Teknologi Malaysia, 81310 Skudai, Johor, Malaysia
} 
$75 \mathrm{ml} / \mathrm{min}$, a conversion of $17 \%$ higher than the corresponding thermodynamic equilibrium conversion was achieved in the CHFMMR. In the operation of the CHFMMR, high purity $\mathrm{H}_{2}$ has been obtained in the shell side, which was $78 \%$ of the total $\mathrm{H}_{2}$ produced in the WGS reaction.

Keywords: Catalytic hollow fibre membrane micro-reactor, Alumina hollow fibre, Hydrogen production, Pd membrane, Sol-gel method

\section{Introduction}

In recent years, interests in the development of micro-reactors for different catalytic reactions have increased due to the advantages that this technology offers in both homogenous and heterogeneous catalysis. The advantages of micro-reactor technology include: high surface area to volume ratio, high heat and/or mass transfer, low pressure drop, good phase contacting, instant mixing of reactants and high selectivity [1-5]. Moreover, micro-reactors can also be used for large scale production since they can easily be scaled up to industrial volumes by multiplying the number of micro-reactors, that additionally makes the system safer [6].

So far, a variety of micro-reactors has been proposed by a number of authors, where the effect of both design aspects and mode of operating conditions on the catalytic performance has been studied [7-9]. The development of commercially viable micro-reactor devices requires low-cost and standard fabrication techniques along with resistant materials that permit the synthesis of appropriate threedimensional micro-channel structures under reaction conditions [10]. Moreover, since the geometric surface of the micro-channels is unable to provide sufficient specific surface area for impregnating catalysts, which are necessary for most of the catalytic 
reactions, chemical treatments and porous coatings must be applied over the surface of the micro-channels walls [11].

On the other hand, although the use of micro-reactors has been reported as a powerful tool that is able to increase significantly the performance of catalytic reactions, the operation of micro-reactor is limited to the equilibrium conversion, similar to the conventional fixed-bed reactor. This limitation can be overcome by including a selective membrane into the micro-reactor design which removes one of the products from the reaction zone. Such concept, i.e. catalytic membrane microreactor, allows not only the reactor to work under optimum reaction conditions but also at significantly lower operating temperature and/or using less amounts of catalyst than conventional reactors, because of combining the reaction and separation steps in one unit.

Recently, we developed an $\mathrm{Al}_{2} \mathrm{O}_{3}$ hollow fibre with an asymmetric pore structure, i.e. a dense sponge-like outer region and an open porous finger-like inner region where a selective membrane and a catalyst can be deposited, respectively [12]. Moreover, the combination of high chemical, thermal and mechanical resistance of $\mathrm{Al}_{2} \mathrm{O}_{3}$ makes it an attractive option for a number of reactions under very different operating conditions. Since the $\mathrm{Al}_{2} \mathrm{O}_{3}$ hollow fibres have a tubular geometry with an outer diameter smaller than $2 \mathrm{~mm}$, it is relatively easy to scale up by bundling the $\mathrm{Al}_{2} \mathrm{O}_{3}$ hollow fibres to a module, which makes the system safer. In comparison with conventional microreactor systems, the $\mathrm{Al}_{2} \mathrm{O}_{3}$ hollow fibre presents an advantage that insignificant heat loss through the tubing by conduction can be realised. In addition, the fact that $\mathrm{Al}_{2} \mathrm{O}_{3}$ hollow fibre lengths as long as $40-50 \mathrm{~cm}$ and as short as $1-2 \mathrm{~cm}$ can be employed, while maintaining their chemical and physical properties, allows their use not only for large-scale but also for small-scale applications such as on- 
board $\mathrm{H}_{2}$ production. Finally, $\mathrm{Al}_{2} \mathrm{O}_{3}$ hollow fibres are synthesised by a dry-wet spinning and phase-inversion technique followed by sintering at high temperature, which is a low-cost and fabrication technique.

The main objective of this work was the development of a catalytic hollow fibre membrane micro-reactor (CHFMMR) for pure $\mathrm{H}_{2}$ production, using the asymmetric $\mathrm{Al}_{2} \mathrm{O}_{3}$ hollow fibre as a substrate for both Pd membrane and catalyst. With this purposes, water-gas shift (WGS) reaction has been chosen to test the performance of the CHFMMR, comparing its performance with a corresponding catalytic hollow fibre micro-reactor (CHFMR) and a fixed-bed reactor.

\section{Experimental}

\subsection{Materials}

$\mathrm{Ce}\left(\mathrm{NO}_{3}\right)_{3} \cdot 6 \mathrm{H}_{2} \mathrm{O} \quad(\geq 99.0 \%$, Fluka Analytical $) \quad \mathrm{Cu}\left(\mathrm{NO}_{3}\right)_{2} .3 \mathrm{H}_{2} \mathrm{O}$ (99.0\%, Acros

Organic), ethylene glycol (99+\%, Acros Organic) and citric acid ( $\geq 99.0 \%$, SigmaAldrich) were used to prepare a homogeneous catalyst solution using the sol-gel Pechini method. $\mathrm{Pd}\left(\mathrm{NH}_{4}\right)_{2} \mathrm{Cl}_{4}$ (ammonium tetrachloropalladate, 99.99\%, Aldrich), $\mathrm{SnCl}_{2} \cdot 2 \mathrm{H}_{2} \mathrm{O}, \mathrm{Na}_{2} \mathrm{EDTA} .2 \mathrm{H}_{2} \mathrm{O}, \mathrm{HCl}(37 \%), \mathrm{N}_{2} \mathrm{H}_{4}, \mathrm{AgNO}_{3}$, and $\mathrm{NH}_{3} \cdot \mathrm{H}_{2} \mathrm{O}(28 \%)$ (Fisher Sci. Ltd) were used for preparing Pd membranes using the electroless plating (ELP) technique.

\subsection{Preparation of $\mathrm{Al}_{2} \mathrm{O}_{3}$ hollow fibre substrates}

Asymmetric $\mathrm{Al}_{2} \mathrm{O}_{3}$ hollow fibre substrates, which have a $1.9 \mathrm{~mm}$ O.D and a $1.0 \mathrm{~mm}$ I.D., have been fabricated by members of our research group through the processes of phase-inversion spinning and sintering technique. The work has been reported in detail elsewhere [12] 
2.3. Impregnation of $30 \% \mathrm{CuO} / \mathrm{CeO}_{2}$ in $\mathrm{Al}_{2} \mathrm{O}_{3}$ hollow fibre for development of CHFMR

$30 \% \mathrm{CuO} / \mathrm{CeO}_{2}$ has been chosen as a catalyst for the WGS reaction, prepared using the sol-gel Pechini method [13]. In a typical preparation, $\mathrm{Ce}\left(\mathrm{NO}_{3}\right)_{3} \cdot 6 \mathrm{H}_{2} \mathrm{O}(17.66 \mathrm{~g})$ and $\mathrm{Cu}\left(\mathrm{NO}_{3}\right)_{2} \cdot 3 \mathrm{H}_{2} \mathrm{O}(9.11 \mathrm{~g})$ were first dissolved in $50 \mathrm{ml}$ deionised water, then followed by citric acid. The amount of copper used in this catalyst was similar to the work reported elsewhere by $\mathrm{Li}$ et al [14]. Citric acid was added to the solution with a mole ratio of citric acid to total metal ions of 2:1. After citric acid was fully dissolved, ethylene glycol was added into the solution with a ratio of citric acid to ethylene glycol of 1:1.2. The solution was further stirred for 24 hours to obtain homogeneous catalyst solution.

In a typical catalyst impregnation, the outer surface of $\mathrm{Al}_{2} \mathrm{O}_{3}$ hollow fibre was wrapped with the PTFE tape to prevent direct contact with the catalyst solution. The catalyst solution was injected using a glass pipette into the lumen of $\mathrm{Al}_{2} \mathrm{O}_{3}$ hollow fibres and this process was repeated several times. The $\mathrm{Al}_{2} \mathrm{O}_{3}$ hollow fibres were later immersed in the catalyst solution before being dried in an oven (Salvislab Thermocenter) at temperatures ranging from $60-90{ }^{\circ} \mathrm{C}$ for 24 hours and further dried at $115{ }^{\circ} \mathrm{C}$ for 2 hours to complete the polymerisation of a polymeric resin precursor. The calcinations process was later carried out at $400{ }^{\circ} \mathrm{C}$ for 1 hour. The catalyst loading in the $\mathrm{Al}_{2} \mathrm{O}_{3}$ hollow fibre was obtained by measuring the weight of $\mathrm{Al}_{2} \mathrm{O}_{3}$ hollow fibre substrates before and after calcinations steps. The mercury intrusion analysis was used to study the effect of impregnation process on the pore size of $\mathrm{Al}_{2} \mathrm{O}_{3}$ hollow fibre. Prior to analysis, samples were broken into sections of approximately $3 \mathrm{~mm}$ in length. Mercury intrusion data was collected at absolute pressure between $1.38 \times 10^{3} \mathrm{~Pa}$ and $2.28 \times 10^{8} \mathrm{~Pa}(0.2-33,000$ psia) (Micromeritics 
Autopore IV) with an equilibrium time of $10 \mathrm{~s}$. The BET surface areas of the $\mathrm{Al}_{2} \mathrm{O}_{3}$ hollow fibre before and after the impregnation process were measured using $\mathrm{N}_{2}$ adsorption isotherms (TriStar 3000). The permeation tests were carried out on bare $\mathrm{Al}_{2} \mathrm{O}_{3}$ hollow fibre and those impregnated with the $30 \% \mathrm{CuO} / \mathrm{CeO}_{2}$ catalyst to study the permeability of the substrate before and after the impregnation process. The SEMEDS analysis (INCA Energy by Oxford Instruments) was carried out to investigate the presence of the WGS catalyst on the inner surface of the $\mathrm{Al}_{2} \mathrm{O}_{3}$ hollow fibre.

\subsection{Fabrication of Pd membrane}

Pd membranes were plated onto the outer surface of $\mathrm{Al}_{2} \mathrm{O}_{3}$ hollow fibres using the ELP technique. Prior to the activation process, $\mathrm{Al}_{2} \mathrm{O}_{3}$ hollow fibres were cleaned using deionised water and activated subsequently by the conventional Pd-Sn activation procedure. The activation process was repeated six times, after which the surface colour of $\mathrm{Al}_{2} \mathrm{O}_{3}$ hollow fibre changed from white to dark brown. The $\mathrm{Al}_{2} \mathrm{O}_{3}$ hollow fibres activated with Pd seeds were then plated with Pd layer using the ELP technique and this process was repeated three times to obtain 6 micron-thick Pd membranes plated on the outer layer of $\mathrm{Al}_{2} \mathrm{O}_{3}$ hollow fibre. These Pd membranes were dried in an oven at $120{ }^{\circ} \mathrm{C}$ for 2 hours (Memmert). The thickness of $\mathrm{Pd}$ membrane was measured using the gravimetric method and it was confirmed using the SEM analysis. The permeation tests using pure $\mathrm{H}_{2}$ and Ar were carried out to study the permeability of Pd membrane and to investigate the presence of pinhole structure on the surface of Pd membrane. 


\subsection{Development of the CHFMMR and the catalytic activity tests}

In the development of the CHFMMR, a single step impregnation has been used to impregnate $30 \% \mathrm{CuO} / \mathrm{CeO}_{2}$ into the finger-like structure of $\mathrm{Al}_{2} \mathrm{O}_{3}$ hollow fibre. The impregnation of $30 \% \mathrm{CuO} / \mathrm{CeO}_{2}$ has been carried out after the fabrication of the Pd membrane in order to avoid the dissolution of copper into the plating solution due to the presence of ammonia and EDTA in the plating solution [15].

The outer surface of the $\mathrm{Al}_{2} \mathrm{O}_{3}$ hollow fibre was coated with a thin and gastight layer of white glaze except the central part of $c a 10 \mathrm{~cm}$, which was left for the plating of the Pd membrane. The Pd membrane was then plated on the outer surface of $\mathrm{Al}_{2} \mathrm{O}_{3}$ hollow fibre using the ELP technique. The $\mathrm{Al}_{2} \mathrm{O}_{3}$ hollow fibre with $\mathrm{Pd}$ membrane on its outer surface was wrapped with the PTFE tape to prevent a direct contact between the catalyst solution and the Pd membranes. A homogeneous catalyst solution was later injected into the lumen of $\mathrm{Al}_{2} \mathrm{O}_{3}$ hollow fibre substrates using a glass pipette and this process was repeated several times. The $\mathrm{Al}_{2} \mathrm{O}_{3}$ hollow fibres were then dried in an oven (Salvislab Thermocenter) at $60{ }^{\circ} \mathrm{C}$ for 24 hours and further dried at $115{ }^{\circ} \mathrm{C}$ to complete the polymerisation of a polymeric resin precursor. The catalyst solution would turn into xerogel, which adsorbed onto the inner surface of $\mathrm{Al}_{2} \mathrm{O}_{3}$ hollow fibre substrates. The oxidation of xerogel formed during the drying process was carried out in a tubular furnace (Vecstar Furnaces, VCTF/SP). The temperature was increased from room temperature to $400{ }^{\circ} \mathrm{C}$ at a rate of $5{ }^{\circ} \mathrm{C}$ and held for 1 hour. A flowing air was introduced into the lumen-side for completing the oxidation process. Argon was introduced on the outer surface of the Pd membrane throughout this process to prevent an oxidation of the Pd membrane which may cause a pin-hole formation. The morphologies of $\mathrm{Al}_{2} \mathrm{O}_{3}$ hollow fibre and the CHFMMR were studied using the scanning electron microscope (SEM) (JEOL JSM-5610LV). 
The catalytic activity tests of the CHFMR were carried out using $\mathrm{Al}_{2} \mathrm{O}_{3}$ hollow fibres (without the Pd membrane on its outer surface) in two distinct configurations, open-both-end configuration and the dead-end configuration, as shown in Fig. 1. The $\mathrm{Al}_{2} \mathrm{O}_{3}$ hollow fibres, shown in Fig. 1a, enabled the reactants to flow through the lumen of $\mathrm{Al}_{2} \mathrm{O}_{3}$ hollow fibres whereas the dead-end configuration, shown in Fig. 1b, forced the reactant to permeate through finger-like structure and sponge-like structure. The open-both-end configuration and the dead-end configuration gave an almost similar CO conversions, showed that the open-both-end configuration used to examine the catalytic activity enabled the reactants to reach the $30 \% \mathrm{CuO} / \mathrm{CeO}_{2}$ catalyst on the inner surface of $\mathrm{Al}_{2} \mathrm{O}_{3}$ hollow fibres.

In order to study the usefulness of the finger-like structure for the WGS reaction, $\mathrm{Al}_{2} \mathrm{O}_{3}$ hollow fibres impregnated with $30 \% \mathrm{CuO} / \mathrm{CeO}_{2}$ catalyst were ground into powder (to eliminate the finger-like region) for using them as a fixed-bed reactor for the sake of comparison. The $\mathrm{Al}_{2} \mathrm{O}_{3}$ powder, with particle size approximately 100 $\mu \mathrm{m}$, was packed into $6 \mathrm{~mm}$ ID ceramic tube. The packed-bed length was approximately $20 \mathrm{~mm}$ and the mass transfer limitation across the bed was negligible.

The catalytic activity tests in a fixed-bed reactor, the CHFMR (without the Pd membrane) and the CHFMMR were carried out under atmospheric pressure over a temperature range of $300{ }^{\circ} \mathrm{C}$ to $500{ }^{\circ} \mathrm{C}$. The feed mixture contains $\mathrm{CO}(5 \%)$ and water vapour which was supplied to the reactor by flowing argon through a glass bubbler containing deionized water at $60{ }^{\circ} \mathrm{C}$. The mole ratio of water vapour to $\mathrm{CO}$ was kept at 0.5 throughout the catalytic activity test. The WGS reactions were carried out at a space velocity of $80,000 \mathrm{~cm}^{3} \mathrm{~g}^{-1} \mathrm{hr}^{-1}$. In a typical catalytic activity test, the weight of the WGS catalyst was $18 \mathrm{mg}$ and the total flow rate was $24 \mathrm{~cm}^{3} \mathrm{~min}^{-1}$. The concentration of the products were measured using a TCD gas chromatography 
(Varian-3900) while the actual flow rate was measured using a bubble flow meter. The GC injections for gas analysis for every reactor used in this study were repeated three times to obtain more reliable results. The CO conversion is defined as follows:

$$
\text { CO conversion }(\%)=\frac{1-F_{C O}^{\text {out }}}{F_{C O}^{\text {in }}} \times 100 \%
$$

In the operation of CHFMMR, $\mathrm{H}_{2}$ produced in the WGS reaction would be separated using the Pd membrane on the outer surface of the CHFMMR. The removal of $\mathrm{H}_{2}$ from the reaction zones was carried out using a co-current flow of a sweep gas to create a concentration gradient across the Pd membrane. The $\mathrm{H}_{2}$ recovery index which represents the ability of Pd membranes to perform $\mathrm{H}_{2}$ permeation is defined as follows:

$$
\mathrm{H}_{2} \text { recovery index }(\%)=\frac{F_{H_{2}}^{\text {Permeate }}}{F_{\mathrm{H}_{2}}^{\text {Permeate }}+F_{\mathrm{H}_{2}}^{\text {Retentate }}} \times 100 \%
$$

\subsection{Results and Discussion}

\section{1 $\mathrm{Al}_{2} \mathrm{O}_{3}$ hollow fibre substrates}

The morphologies of the $\mathrm{Al}_{2} \mathrm{O}_{3}$ hollow fibres, used as a substrate for both the $\mathrm{Pd}$ membrane and the $30 \% \mathrm{CuO} / \mathrm{CeO}_{2}$ catalyst in the development of the CHFMMR, were studied using the SEM. Fig. 2a-b shows the SEM images of the cross sections of an $\mathrm{Al}_{2} \mathrm{O}_{3}$ hollow fibre at different magnifications. As can be seen, $\mathrm{Al}_{2} \mathrm{O}_{3}$ hollow fibre prepared by a phase-inversion technique followed by sintering process at a high temperature has an asymmetric pore structure, which consisted of finger-like voids approximately $80 \%$ of the fibre cross-section with the remaining $20 \%$ consisting of a sponge-like region [12]. At a higher SEM magnification, the difference in the pore size distributions between the finger-like structure and the sponge-like region can be examined. The narrow pore size distribution of sponge-like structures enabled the 
deposition of a thin Pd membrane on the outer surface of the $\mathrm{Al}_{2} \mathrm{O}_{3}$ hollow fibre whereas the open pore structure of the finger-like region enabled the impregnation of the $30 \% \mathrm{CuO} / \mathrm{CeO}_{2}$ catalyst in the inner surface of the $\mathrm{Al}_{2} \mathrm{O}_{3}$ hollow fibre.

\subsection{Impregnation of $30 \% \mathrm{CuO} / \mathrm{CeO}_{2}$ into the $\mathrm{Al}_{2} \mathrm{O}_{3}$ hollow fibre}

The impregnations of $30 \% \mathrm{CuO} / \mathrm{CeO}_{2}$ catalyst into the finger-like structure of the $\mathrm{Al}_{2} \mathrm{O}_{3}$ hollow fibre were carried out using the sol-gel Pechini method [13]. Conventionally, the drying processes of various catalyst solutions using the sol-gel Pechini method are carried out at temperatures ranging from $90{ }^{\circ} \mathrm{C}$ to $150{ }^{\circ} \mathrm{C}$ to facilitate the polymerization process between ethylene glycol and citric acid [13]. The impregnations of $30 \% \mathrm{CuO} / \mathrm{CeO}_{2}$ into $\mathrm{Al}_{2} \mathrm{O}_{3}$ hollow fibre had been carried out using the conventional approach but the amount of the catalyst obtained was very low because the sol-gel formed in this process swelled and spread, leaving the inner surface of $\mathrm{Al}_{2} \mathrm{O}_{3}$ hollow fibre substrates, consequently caused a reduction in the amount of $\mathrm{CuO} / \mathrm{CeO}_{2}$. Therefore, a reduction in the drying temperature was essential to ensure a maximum amount of $\mathrm{CuO} / \mathrm{CeO}_{2}$ could be impregnated onto the inner surface of the $\mathrm{Al}_{2} \mathrm{O}_{3}$ hollow fibre.

In this study, two-step drying processes were carried out to turn homogeneous catalyst solution to xerogel and to increase the amount of catalyst in the inner surface of $\mathrm{Al}_{2} \mathrm{O}_{3}$ hollow fibre. The pre-drying process was first carried out at temperatures ranging from $60{ }^{\circ} \mathrm{C}-90{ }^{\circ} \mathrm{C}$ to allow the removal of excess solvent (water) and to avoid excessive swelling of sol-gel which could reduce the amount of $30 \% \mathrm{CuO} / \mathrm{CeO}_{2}$ in $\mathrm{Al}_{2} \mathrm{O}_{3}$ hollow fibre. Fig. 3 the amount of $30 \% \mathrm{CuO} / \mathrm{CeO}_{2}$ impregnated into the inner surface of $\mathrm{Al}_{2} \mathrm{O}_{3}$ hollow fibre, which show a slight increase when the pre-drying temperature was decreased from $90{ }^{\circ} \mathrm{C}$ to $60{ }^{\circ} \mathrm{C}$. The pre-drying process was 
recognized as a crucial step that could influence the amount of catalyst during the solgel impregnation. The maximum amount of $30 \% \mathrm{CuO} / \mathrm{CeO}_{2}$ could be impregnated was around $6 \%$ when the pre-drying process was carried out at $60{ }^{\circ} \mathrm{C}$ and this condition has been chosen for the impregnation of the catalyst into $\mathrm{Al}_{2} \mathrm{O}_{3}$ hollow fibre in the development of the CHFMR and the CHFMMR.

Fig. 4 shows the mercury intrusion data for $\mathrm{Al}_{2} \mathrm{O}_{3}$ hollow fibres before and after the impregnation process. Two different pore size distributions corresponding to the sponge-like structure $\left(d_{p}=0.1 \mu \mathrm{m}\right)$ and the entrance of the finger-like voids $\left(d_{p}=\right.$ $10 \mu \mathrm{m})$ can be clearly seen. After impregnated with $30 \% \mathrm{CuO} / \mathrm{CeO}_{2}$, the pore size distribution in the sponge-like region and finger-like structure decreased from 0.15 to $0.08 \mu \mathrm{m}$ and from 9.17 to $8.97 \mu \mathrm{m}$, respectively. The impregnation of the $30 \% \mathrm{CuO} / \mathrm{CeO}_{2}$ catalyst into $\mathrm{Al}_{2} \mathrm{O}_{3}$ hollow fibres reduced the size of micro-pores and macro-pores in both regions but a significant decrease can be seen in the size of micro-pores in the sponge-like region. The reduction in the pore size distribution in both regions can be associated with the ability of a homogeneous catalyst solution to diffuse through a transverse network of narrow channels and to form a highly porous xerogel after being subjected to a drying process. The calcination process, which carried out afterward, oxidised the xerogel into catalyst particles which partially filled the pores of $\mathrm{Al}_{2} \mathrm{O}_{3}$ hollow fibre substrate.

The specific surface area of the $\mathrm{Al}_{2} \mathrm{O}_{3}$ hollow fiber increased from 2.2 to 7.1 $\mathrm{m}^{2} / \mathrm{g}$ after a catalyst impregnation process. The presence of $30 \% \mathrm{CuO} / \mathrm{CeO}_{2}$ in the inner surface of $\mathrm{Al}_{2} \mathrm{O}_{3}$ hollow fibre impregnated using the sol-gel Pechini method resulted in an increase in the specific surface area of the $\mathrm{Al}_{2} \mathrm{O}_{3}$ hollow fiber. It has been known that the mixed oxides produced using the sol-gel Pechini method has higher specific surface areas compared to other conventional approaches [16]. 
Permeation tests were carried out using pure $\mathrm{N}_{2}$ on the $\mathrm{Al}_{2} \mathrm{O}_{3}$ hollow fibre before and after impregnated with $30 \% \mathrm{CuO} / \mathrm{CeO}_{2}$ to study the effect of the catalyst impregnation process on the permeability of the $\mathrm{Al}_{2} \mathrm{O}_{3}$ hollow fibres and the results are shown in Fig. 5. The permeation data for a bare substrate suggested that $\mathrm{Al}_{2} \mathrm{O}_{3}$ hollow fibres consisted of the finger-like structure and the sponge-like region was permeable to $\mathrm{N}_{2}$. The permeability of $\mathrm{Al}_{2} \mathrm{O}_{3}$ hollow fibres reduced when $30 \% \mathrm{CuO} / \mathrm{CeO}_{2}$ was impregnated into its inner surface and a $27 \%$ decrease in the $\mathrm{N}_{2}$ permeability was observed at the highest pressure difference. This occurred due to the presence of $30 \% \mathrm{CuO} / \mathrm{CeO}_{2}$ that reduced the micro-channel volume particularly in the sponge-like region.

In the operation of CHFMMR, the pressure difference across $\mathrm{Al}_{2} \mathrm{O}_{3}$ hollow fibre was negligible because the separation of $\mathrm{H}_{2}$ from reaction zone was carried out using a sweep gas. The permeability data in Fig. 5 suggests that permeability difference between bare $\mathrm{Al}_{2} \mathrm{O}_{3}$ hollow fibres and those impregnated with $30 \% \mathrm{CuO} / \mathrm{CeO}_{2}$ was negligible when the pressure difference used in the permeation test was very low. Asymmetric $\mathrm{Al}_{2} \mathrm{O}_{3}$ hollow fibres impregnated with $30 \% \mathrm{CuO} / \mathrm{CeO}_{2}$ still have higher permeability which sufficient for reaction products, produced during the WGS reaction, to reach Pd membrane on the outer surface of $\mathrm{Al}_{2} \mathrm{O}_{3}$ hollow fibres and it could still be used as a substrate for both the Pd membrane and the catalyst in the development of the CHFMMR.

An elemental analysis using the SEM-EDS surface mapping technique was carried out on the cross-section of $\mathrm{Al}_{2} \mathrm{O}_{3}$ hollow fibres to study the dispersion and distribution of the $30 \% \mathrm{CuO} / \mathrm{CeO}_{2}$ catalyst. Fig. 6 shows the presence of $\mathrm{Cu}$ and $\mathrm{Ce}$ after the impregnation process. An asymmetric distribution of $30 \% \mathrm{CuO} / \mathrm{CeO}_{2}$ catalyst in the finger-like region showed that more catalyst particles can be seen on the region 
that close to the $\mathrm{Al}_{2} \mathrm{O}_{3}$ hollow fiber lumen side. This behaviour might be associated with an insufficient driving force to push excess catalyst sol-gel deeper into the finger-like structure and this caused an accumulation of the $30 \% \mathrm{CuO} / \mathrm{CeO}_{2}$ catalyst in the narrow threshold of this structure. However, a uniform dispersion for both $\mathrm{Cu}$ and Ce on the cross-section of the substrate indicated that the sol-gel Pechini method successfully dispersed the $30 \% \mathrm{CuO} / \mathrm{CeO}_{2}$ catalyst into the $\mathrm{Al}_{2} \mathrm{O}_{3}$ hollow fibres.

\subsection{Deposition of the Pd membrane onto $\mathrm{Al}_{2} \mathrm{O}_{3}$ hollow fibre substrates}

The outer surface of $\mathrm{Al}_{2} \mathrm{O}_{3}$ hollow fibre was seeded with Pd particles using a conventional activation process before the deposition of Pd membrane. This process has been recognised as a crucial step for growing a uniform and dense Pd membrane [17]. Fig. 7a and Fig. 7b shows the outer surface of the $\mathrm{Al}_{2} \mathrm{O}_{3}$ hollow fibre before the activation process and after 6 activation steps, respectively. After 6 activation steps, the outer surface of $\mathrm{Al}_{2} \mathrm{O}_{3}$ hollow fibre has been fully covered with Pd clusters with an average particle size of $50 \mathrm{~nm}$ as shown in Fig. 2b. The use of $\mathrm{Al}_{2} \mathrm{O}_{3}$ hollow fibre as the support for Pd membrane eliminated the necessity of using an intermediate layer, which is typically applied to close macropores and prevent the intermetallic diffusion at higher temperatures, due to a small and narrow pore size distribution of sponge-like region in the outer layer and stability of $\mathrm{Al}_{2} \mathrm{O}_{3}$ at higher temperatures $[18,19]$. The Pd membrane obtained using the ELP technique is shown in Fig. 7c. The thickness of the Pd membrane was $6 \mu \mathrm{m}$, which was close to $5.4 \mu \mathrm{m}$ estimated by the gravimetric method. According to Ma et al., [20] the thickness of Pd layer has to be at least three times higher than the maximum pore diameter of a porous substrate to avoid leaks on the surface of Pd membrane. Although the actual thickness of the Pd membrane used in this study was higher than its theoretical value (the largest porous 
size was around $0.3 \mu \mathrm{m}$ ), it was an advantage in avoiding the formation of defects due to the sintering of Pd particles at high temperatures during the WGS reaction [21]. Fig. $7 \mathrm{~d}$ shows that the Pd membrane on the outer surface of $\mathrm{Al}_{2} \mathrm{O}_{3}$ hollow fibre plated using ELP technique has homogeneous and uniform surface and free from defects.

Permeation tests were carried out on the Pd membrane using pure $\mathrm{H}_{2}$ and $\mathrm{Ar}$ gases in order to test the $\mathrm{H}_{2}$ permeability and $\mathrm{H}_{2} / \mathrm{Ar}$ selectivity before being used in the CHFMMR. Fig. 8a shows the $\mathrm{H}_{2}$ permeation flux through the Pd membrane as a function of square root pressure difference estimated between shell and lumen side pressures. The graph shows that the permeation of $\mathrm{H}_{2}$ increased as the temperature and/or the pressure in the lumen of $\mathrm{Al}_{2} \mathrm{O}_{3}$ hollow fibre was increased. The linear fit shows that the $\mathrm{H}_{2}$ permeation through the Pd membrane followed the Sievert's law. From Fig. 8, the $\mathrm{H}_{2}$ permeances of Pd membrane were 6.9, 8.3, 9.5 and $10.7 \mathrm{~L} \cdot \mathrm{m}^{-2} . \mathrm{s}^{-}$ ${ }^{1}$.atm ${ }^{-1 / 2}$ at 300, 350, 400 and $450{ }^{\circ} \mathrm{C}$, respectively. On the other hand, Ar did not permeate through the Pd membrane at any testing conditions applied during the permeation tests, showed an infinite selectivity of the Pd membrane towards $\mathrm{H}_{2}$. Based on these results, it can be concluded that the Pd membrane plated on the $\mathrm{Al}_{2} \mathrm{O}_{3}$ hollow fibre was absolutely dense and free from defects, which was in agreement with the result obtained in the SEM analysis as shown in Fig. 7d.

\subsection{The WGS reaction in a catalytic hollow fibre membrane micro-reactor}

\section{(CHFMMR)}

A comparative study of the CO conversion obtained in the WGS reaction as a function of the reaction temperatures in a fixed-bed reactor, the CHFMR and the CHFMMR using different flow rates of a sweep gas are shown in Fig. 8. Experimental error of data points shown in Fig. 9 was below $\pm 4.9 \%$. Under similar 
reaction conditions, a $23 \%$ increase in the $\mathrm{CO}$ conversion was obtained in the CHFMR compared to the fixed-bed reactor. The improvement in the catalyst activity was due to the presence of a thin layer of the $30 \% \mathrm{CuO} / \mathrm{CeO}_{2}$ catalyst with a high surface area on the inner surface of $\mathrm{Al}_{2} \mathrm{O}_{3}$ hollow fibres. The use of $\mathrm{Al}_{2} \mathrm{O}_{3}$ hollow fibres as a substrate resulted in a more efficient utilization of the $30 \% \mathrm{CuO} / \mathrm{CeO}_{2}$ catalyst compared to its conventional counterparts such as pellets or extrudates. In addition, the finger-like region can be considered as a set of hundreds of conical micro-channels that were perpendicularly distributed around the lumen of the $\mathrm{Al}_{2} \mathrm{O}_{3}$ hollow fiber. In these micro-channels, the reactants were efficiently mixed and this contributed to an increase in the CO conversion. The result also shows that the CO conversion of the CHFMR increased to its equilibrium value when the reaction temperature was increased to $500{ }^{\circ} \mathrm{C}$.

The thin Pd membrane plated on the outer surface of the CHFMMR enabled the separation of $\mathrm{H}_{2}$ produced during the reaction from the reaction zone, resulted in an increase in the CO conversion up to $20 \%$ from the corresponding values of the CHFMR. The increase in the CO conversion can be explained in accordance with the “Le Chatelier” principle, the removal of one or more reaction products will shift the conversion towards products formation. It is interesting to note that at $500{ }^{\circ} \mathrm{C}$ and a sweep gas flow rate of $75 \mathrm{ml} / \mathrm{min}$, the CO conversion increased from $45 \%$ in the CHFMR to $60 \%$ in the CHFMMR, which was $15 \%$ higher than the thermodynamic equilibrium value. Fig. 10a also shows that the production rate of $\mathrm{CO}_{\mathrm{X}}$ free $\mathrm{H}_{2}$ from the CHFMMR was influenced by the reaction temperatures and the sweep flow rates, showed that the Sievets' law governed the $\mathrm{H}_{2}$ transport through the Pd membrane.

In order to study the performance of the Pd membrane during the operation of the CHFMMR, the $\mathrm{H}_{2}$ recovery index was calculated at different temperatures and 
the flow rates of the sweep gas shown in Fig. 10b. This index is typically used to describe the efficiency of Pd membranes and can be defined as the $\mathrm{H}_{2}$ fraction permeated through the Pd membrane with respect to the total amount of $\mathrm{H}_{2}$ produced during the WGS reaction. As can be seen, $\mathrm{H}_{2}$ recovery index for every sweep factors remained constant as the temperature was increased from $300{ }^{\circ} \mathrm{C}$ to $500{ }^{\circ} \mathrm{C}$, indicated the reaction temperature has an insignificant effect on permeability of the $\mathrm{Pd}$ membrane. However, the $\mathrm{H}_{2}$ recovery index increased as the flow rate of the sweep gas was increased. The higher the flow rate of the sweep gas, the higher the pressure difference across the Pd layer, thus increased the $\mathrm{H}_{2}$ permeability through the Pd membrane.

In the operation of the CHFMMR, high purity $\mathrm{H}_{2}$ has been obtained in the shell side, which was $78 \%$ of the total $\mathrm{H}_{2}$ produced in the WGS reaction. Higher recovery of $\mathrm{H}_{2}$ was obtained in the shell-side of the CHFMMR although the pressure difference across the Pd membrane was only induced using the sweep gas. It is predicted that the $\mathrm{H}_{2}$ recovery index might still be increased up to $100 \%$, which represent a complete removal of $\mathrm{H}_{2}$ from reaction zone, if the sweep gas is replaced by the use of vacuum extraction in the shell side of the CHFMMR.

It is important to highlight that the Pd membrane shown good stability even though it was heated at higher temperatures and used for long periods of time during the WGS reaction. All the CHFMMR prepared and tested in this work in WGS reactor have shown a good reproducibility.

\section{Conclusions}

This study demonstrates that $\mathrm{Al}_{2} \mathrm{O}_{3}$ hollow fibre, which has an asymmetric porous structure, can be used as a single substrate for both the Pd membrane and the 
$30 \% \mathrm{CuO} / \mathrm{CeO}_{2}$ catalyst in the development of a CHFMMR for $\mathrm{CO}_{\mathrm{X}}$ free $\mathrm{H}_{2}$ production. The finger-like region in the $\mathrm{Al}_{2} \mathrm{O}_{3}$ hollow fibre was made up by a set of hundreds of conical micro-channels which were perpendicularly distributed around the fibre lumen in which the reactants could be efficiently mixed.

A thin layer of $30 \% \mathrm{CuO} / \mathrm{CeO}_{2}$ catalyst with a high surface area was successfully deposited into $\mathrm{Al}_{2} \mathrm{O}_{3}$ hollow fibres using the sol-gel Pechini method. The use of $\mathrm{Al}_{2} \mathrm{O}_{3}$ hollow fibres resulted in a more efficient utilization of the $30 \% \mathrm{CuO} / \mathrm{CeO}_{2}$ catalyst compared to its conventional counterparts such as pellets or extrudates. This makes $\mathrm{Al}_{2} \mathrm{O}_{3}$ hollow fibres as a efficient support not only for the Pd membrane but also for the $30 \% \mathrm{CuO} / \mathrm{CeO}_{2}$ catalyst. The maximum amount of $30 \% \mathrm{CuO} / \mathrm{CeO}_{2}$ catalysts deposited into the finger-like region of the $\mathrm{Al}_{2} \mathrm{O}_{3}$ hollow fibre was approximately $6 \%$ when the drying process was carried out at $60{ }^{\circ} \mathrm{C}$.

The catalytic activity results obtained for the WGS reaction in a fixed-bed reactor, the CHFMR and the CHFMMR showed that the conversion in a CHFMMR was the highest. At $500{ }^{\circ} \mathrm{C}$ and at a sweep flow rate of $75 \mathrm{ml} / \mathrm{min}$, the conversion increased from $43 \%$ in a CHMFR to 60\% in a CHFMMR, which was $17 \%$ higher than the corresponding thermodynamic equilibrium conversion. In addition, high purity $\mathrm{H}_{2}$ has been produced in the shell side of the CHFMMR during the WGS reaction. This study shows that $\mathrm{H}_{2}$ permeability through the $\mathrm{Pd}$ membrane increases with temperature and sweep gas flow rate. The Pd membrane plated on the $\mathrm{Al}_{2} \mathrm{O}_{3}$ hollow fibre, with a thickness of approximately $6 \mu \mathrm{m}$ and a defect-free surface, showed an good stability during the WGS reaction, even though it was used at higher temperatures for long periods of time.

Based upon these results, the CHFMMR offers important advantages over existing $\mathrm{H}_{2}$ production systems and can be presented as a promising system to 
produces $\mathrm{CO}_{\mathrm{x}}$ free $\mathrm{H}_{2}$ by WGS reaction. Furthermore, the fabrication techniques and process understanding generated from this study are generic and may be applied to a wide range of heterogeneously catalysed gas phase reactions which are related to $\mathrm{H}_{2}$ production.

\section{Acknowledgements}

The authors gratefully acknowledge the research funding provided by EPSRC in the United Kingdom (grant No.EP/G01244X/1). M.A. Rahman would like to extend his gratitude to Dr. Wu Zhentao for his assistance in this work.

\section{References}

[1] Y. Han and N. Shikazono, Measurement of liquid film thickness in micro square channel, International Journal of Multiphase Flow 35 (10) (2009) 896-903.

[2] N. Dupont, G. Germani, A.C. van Veen, Y. Schuurman, G. Schafer, and C. Mirodatos, Specificities of micro-structured reactors for hydrogen production and purification, International Journal of Hydrogen Energy 32 (10-11) (2007) 1443-1449.

[3] S. Tadepalli, R. HaIder, and A. Lawal, Catalytic hydrogenation of o-nitroanisole in a microreactor: Reactor performance and kinetic studies, Chemical Engineering Science 62 (10) (2007) 2663-2678.

[4] H. Nagasawa and K. Mae, Development of a new microreactor based on annular microsegments for fine particle production, Industrial \& Engineering Chemistry Research 45 (7) (2006) 2179-2186. 
[5] K. Sreenath and S. Pushpavanam, Issues in the scaling of exothermic reactions: From micro-scale to macro-scale, Chemical Engineering Journal 155 (1-2) (2009) 312-319.

[6] Y. Kikutani, A. Hibara, K. Uchiyama, H. Hisamoto, M. Tokeshi, and T. Kitamori, Pile-up glass microreactor, Lab on A Chip 2 (4) (2002) 193-196.

[7] C. Horny, L. Kiwi-Minsker, and A. Renken, Micro-structured string-reactor for autothermal production of hydrogen, Chemical Engineering Journal 101 (1-3) (2004) 3-9.

[8] I. Yuranov, A. Renken, and L. Kiwi-Minsker, Zeolite/sintered metal fibers composites as effective structured catalysts, Applied Catalysis A-General 281 (1-2) (2005) 55-60.

[9] J.M. Bae, S. Ahmed, R. Kumar, and E. Doss, Microchennel development for autothermal reforming of hydrocarbon fuels, Journal of Power Sources 139 (1-2) (2005) 91-95.

[10] P. Watts and C. Wiles, Recent advances in synthetic micro reaction technology, Chemical Communications (5) (2007) 443-467.

[11] L. Kiwi-Minsker and A. Renken, Microstructured reactors for catalytic reactions, Catalysis Today 110 (1-2) (2005) 2-14.

[12] B.F.K. Kingsbury and K. Li, A morphological study of ceramic hollow fibre membranes, Journal of Membrane Science 328 (1-2) (2009) 134-140.

[13] M. Kakihana, "Sol-Gel" preparation of high temperature superconducting oxides, Journal of Sol-Gel Science and Technology 6 (1) (1996) 7-55.

[14] L. Li, Y.Y. Zhan, Q. Zheng, Y.H. Zheng, X.Y. Lin, D.L. Li, and J.J. Zhu, Water-gas shift reaction over aluminum promoted $\mathrm{Cu} / \mathrm{CeO} 2$ nanocatalysts 
characterized by XRD, BET, TPR and cyclic voltammetry (CV), Catalysis Letters 118 (1-2) (2007) 91-97.

[15] E.Y. Nevskaya, I.G. Gorichev, S.B. Safronov, B.E. Zaitsev, A.M. Kutepov, and A.D. Izotov, Interaction between copper(II) oxide and aqueous ammonia in the presence of ethylenediaminetetraacetic acid, Theoretical Foundations of Chemical Engineering 35 (5) (2001) 503-509.

[16] R.D. Gonzalez, T. Lopez, and R. Gomez, Sol-gel preparation of supported metal catalysts, Catalysis Today 35 (3) (1997) 293-317.

[17] Y.S. Cheng and K.L. Yeung, Effects of electroless plating chemistry on the synthesis of palladium membranes, Journal of Membrane Science 182 (1-2) (2001) 195-203.

[18] Y.H. Ma, B.C. Akis, M.E. Ayturk, F. Guazzone, E.E. Engwall, and I.P. Mardilovich, Characterization of intermetallic diffusion barrier and alloy formation for $\mathrm{Pd} / \mathrm{Cu}$ and $\mathrm{Pd} / \mathrm{Ag}$ porous stainless steel composite membranes, Industrial \& Engineering Chemistry Research 43 (12) (2004) 2936-2945.

[19] P.P. Mardilovich, Y. She, Y.H. Ma, and M.H. Rei, Defect-free palladium membranes on porous stainless-steel support, Aiche Journal 44 (2) (1998) 310322.

[20] Y.H. Ma, I.P. Mardilovich, and P.P. Mardilovich, Effects of porosity and pore size distribution of the porous stainless steel on the thickness and hydrogen flux of palladium membranes, 462001 154-156

[21] W.J. Shen, A. Kobayashi, Y. Ichihashi, Y. Matsumura, and M. Haruta, Growth of Pd particles in methanol synthesis over Pd/CeO2, Catalysis Letters 73 (2-4) (2001) 161-165. 


\section{Figure Captions}

Fig. 1 Schematic diagram of operational modes for the CHFMR

Fig. 2 SEM pictures of an $\mathrm{Al}_{2} \mathrm{O}_{3}$ hollow fibre at different magnifications before Pd deposition and catalyst impregnation.

Fig. 3 Catalyst loading deposited into the finger-like region of the $\mathrm{Al}_{2} \mathrm{O}_{3}$ hollow fibre as a function of the drying temperature.

Fig. 4 Hg porosimetry of $\mathrm{Al}_{2} \mathrm{O}_{3}$ hollow fibre before (-) and after (---) catalyst impregnation.

Fig. 5 Fluxes of $\mathrm{N}_{2}$ through the $\mathrm{Al}_{2} \mathrm{O}_{3}$ hollow fibre as a function of the transmembrane pressure before ( $\mathbf{\square})$ and after ( $\square$ ) catalysts impregnation.

Fig. $6 \mathrm{Cu}$ and Ce distribution SEM-EDS images of the $\mathrm{Al}_{2} \mathrm{O}_{3}$ hollow fibers after catalyst impregnation.

Fig. 7 SEM pictures of the top surface of the $\mathrm{Al}_{2} \mathrm{O}_{3}$ hollow fibre before (a) and after (b) activation process (c) cross-section of the $\mathrm{Al}_{2} \mathrm{O}_{3}$ hollow fibre after Pd deposition and d) top surface of Pd membrane.

Fig. 8 a) Fluxes of $\mathrm{H}_{2}$ through the Pd membrane as a function of the difference in the square roots of the transmembrane pressure at different temperatures:

(•) $300^{\circ} \mathrm{C},(\bullet) 350^{\circ} \mathrm{C},(\boldsymbol{\Delta}) 400^{\circ} \mathrm{C}$ and $(\bullet) 450^{\circ} \mathrm{C}$.

Fig. 9 Conversion as a function of the temperature in WGS reaction: ( $\cdots)$ thermodynamic equilibrium, ( $\square$ ) fixed-bed reactor, (०) the CHFMR and the CHFMMR using different flow rates of sweep gas: (ש) $50 \mathrm{ml} / \mathrm{min}$, $65 \mathrm{ml} / \mathrm{min}$ and $(\bullet) 70 \mathrm{ml} / \mathrm{min}$.

Fig. 10 a) $\mathrm{H}_{2}$ permeation through the Pd membrane during WGS reaction as a function of the temperature at different sweep gas flow rates: (a) 50 $\mathrm{ml} / \mathrm{min},(\boldsymbol{\Delta}) 65 \mathrm{ml} / \mathrm{min}$ and $(\bullet) 70 \mathrm{ml} / \mathrm{min}$. b) $\mathrm{H}_{2}$ recovery index as a 
function of the reaction temperature at different sweep gas flow rates: (a) $50 \mathrm{ml} / \mathrm{min},(\boldsymbol{\Delta}) 65 \mathrm{ml} / \mathrm{min}$ and $(\bullet) 70 \mathrm{ml} / \mathrm{min}$. 
Figures

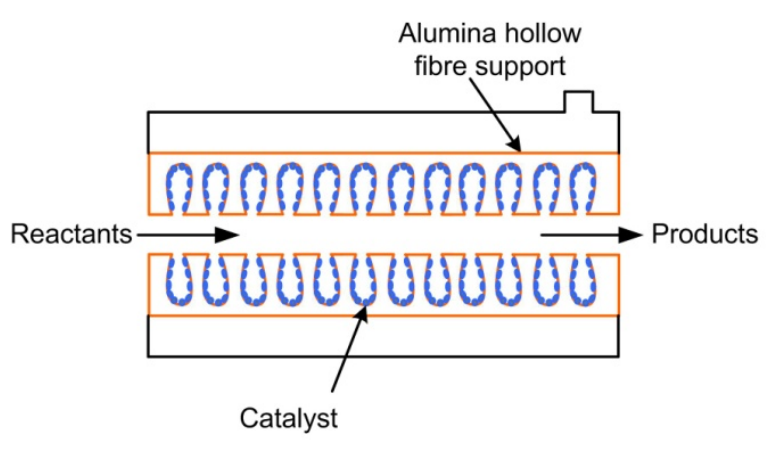

a) open-both-end configuration

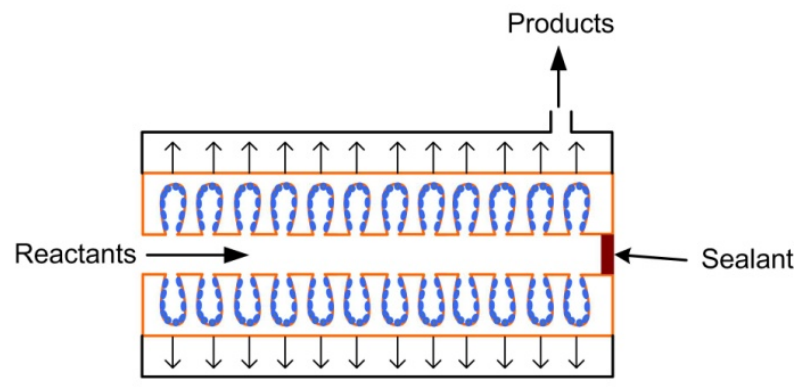

b) dead-end configuration

Fig. 1 

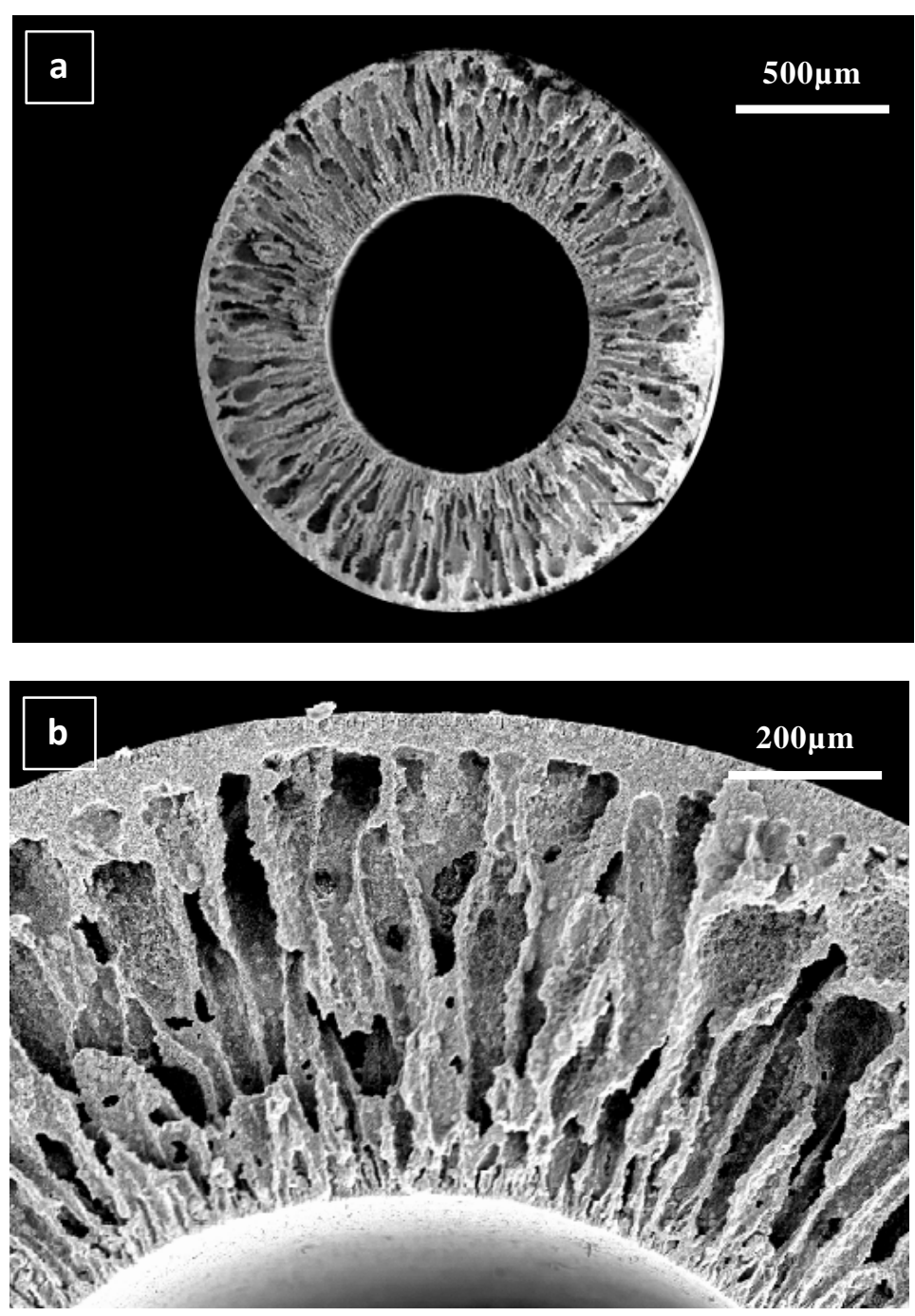

Fig. 2 


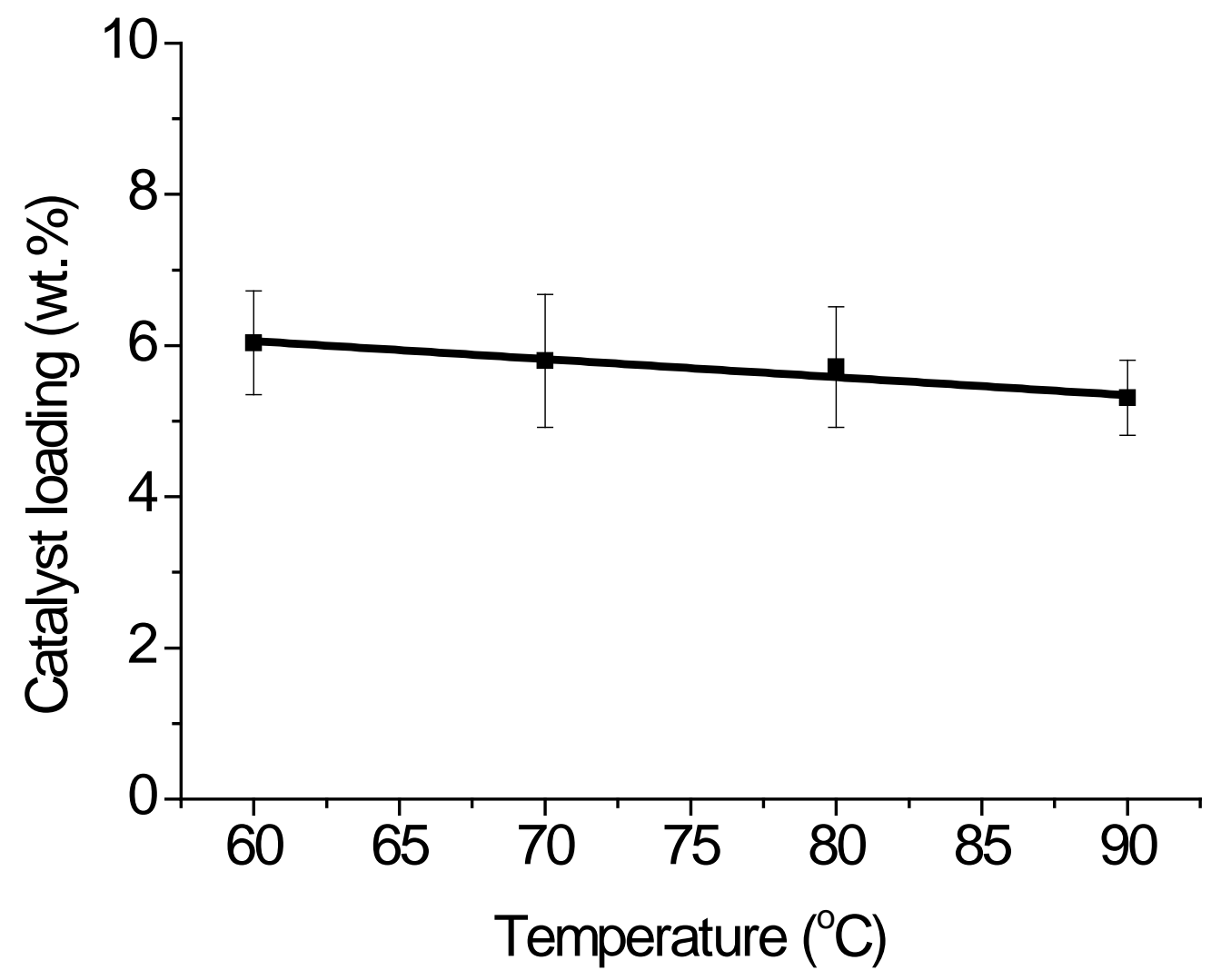

Fig. 3 


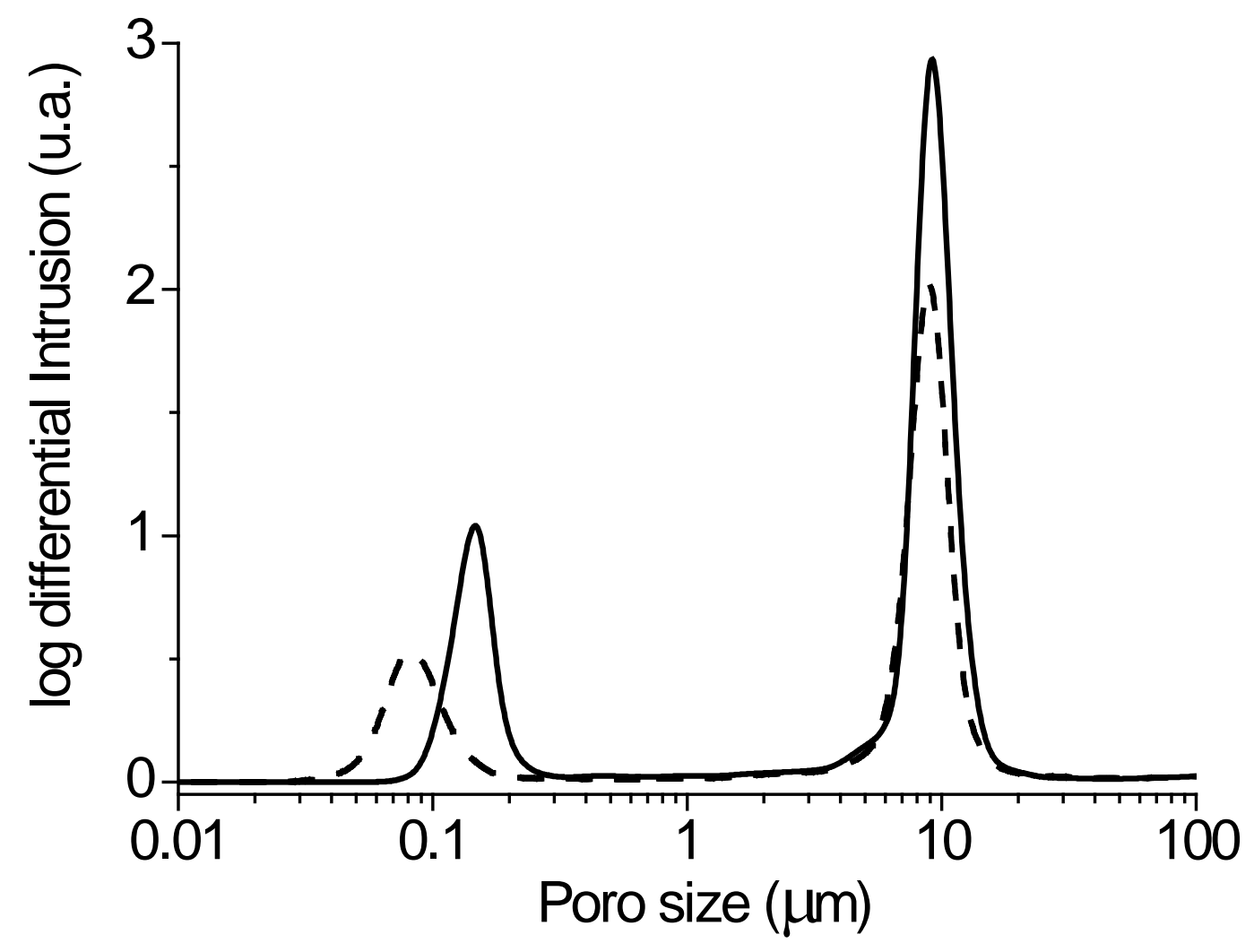

Fig. 4 


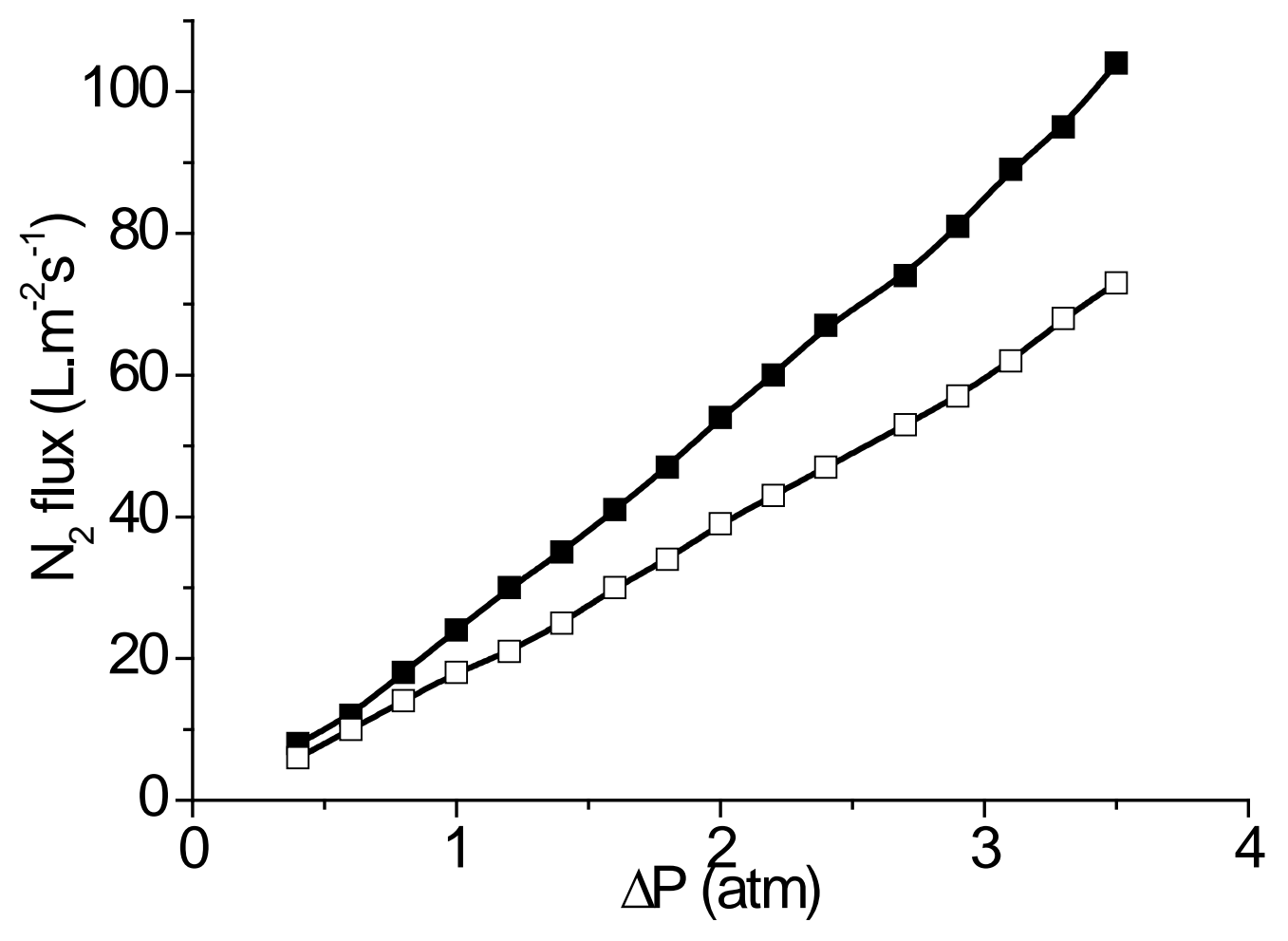

Fig. 5 

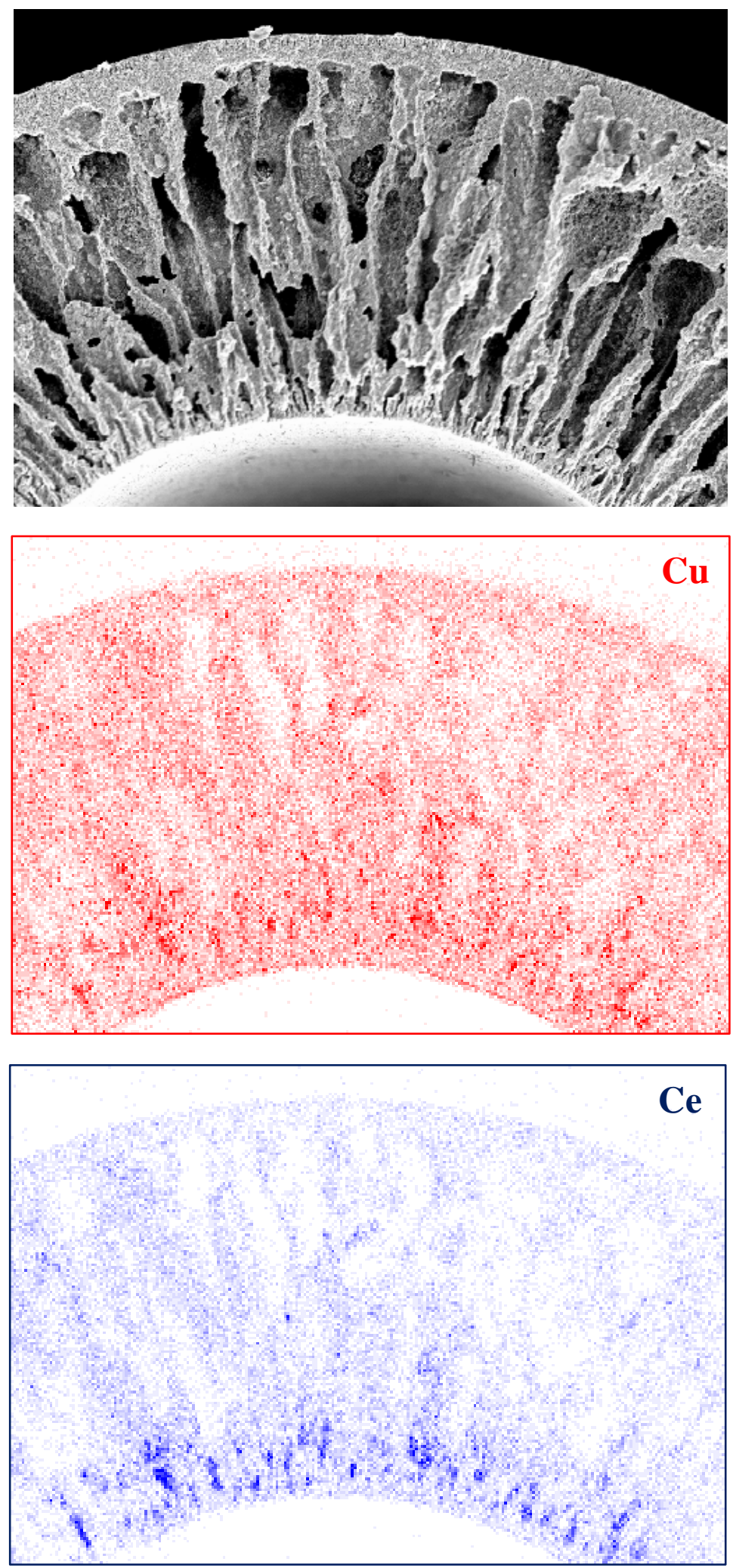

Fig. 6 

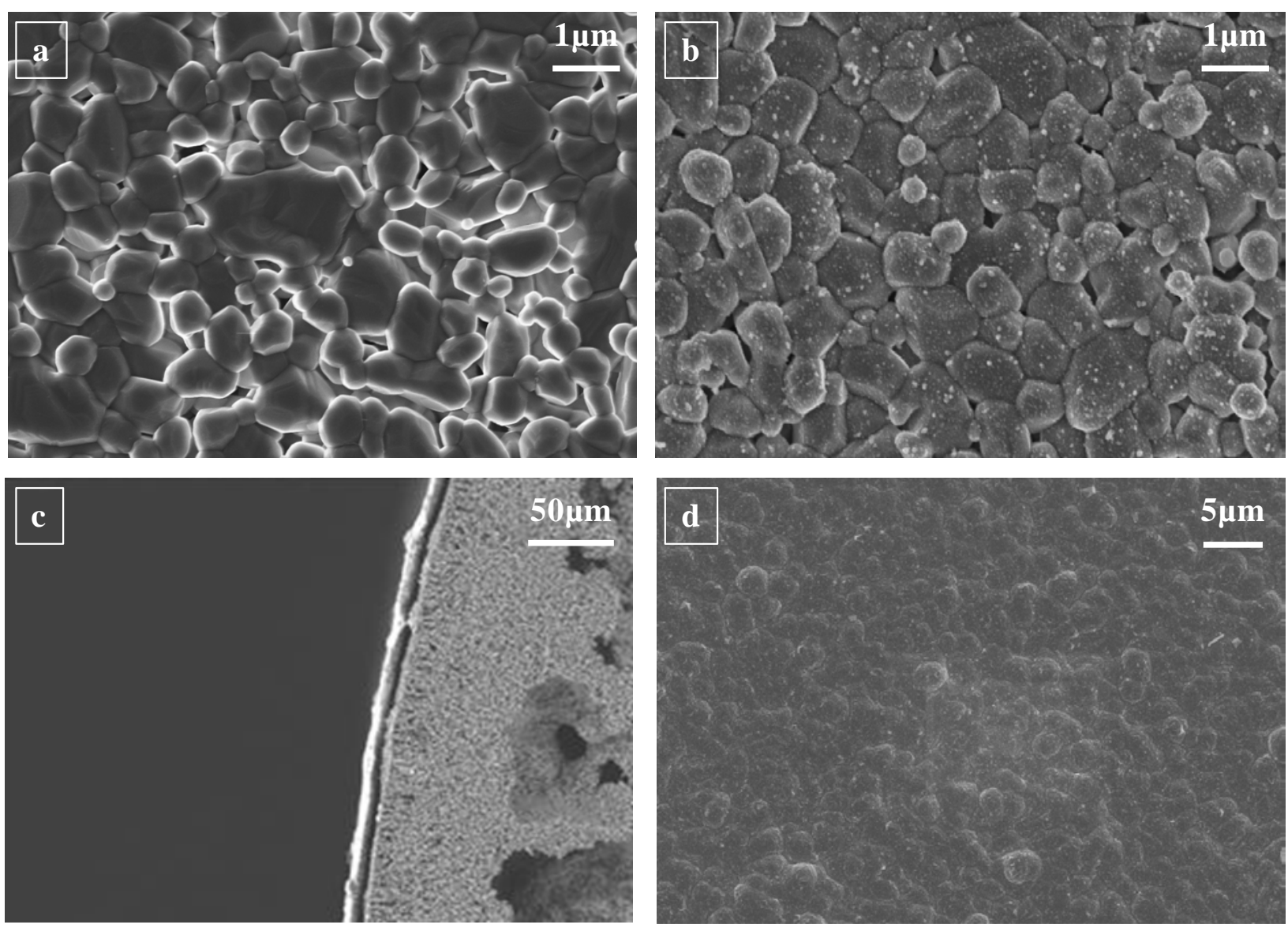

Fig. 7 


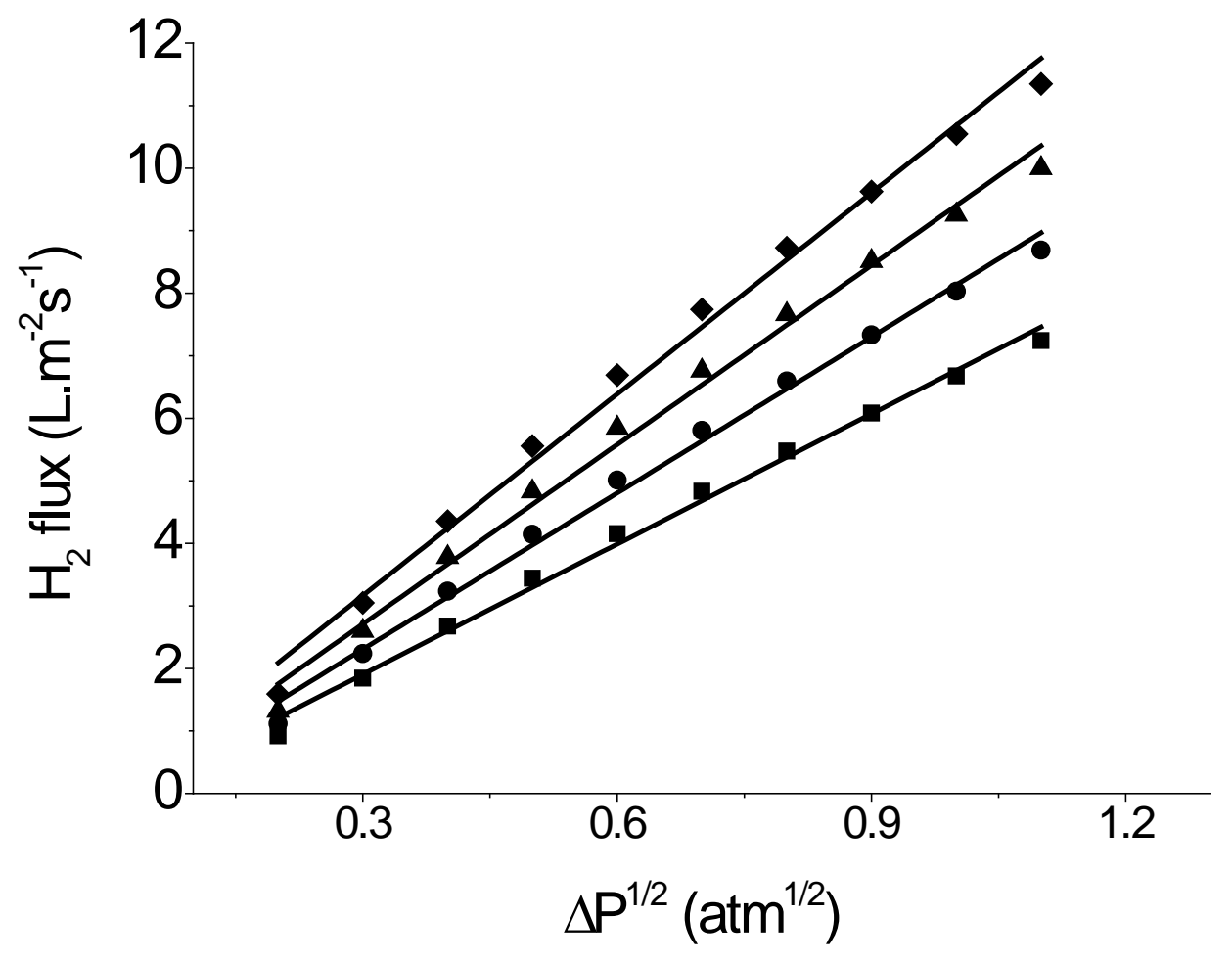

Fig. 8 


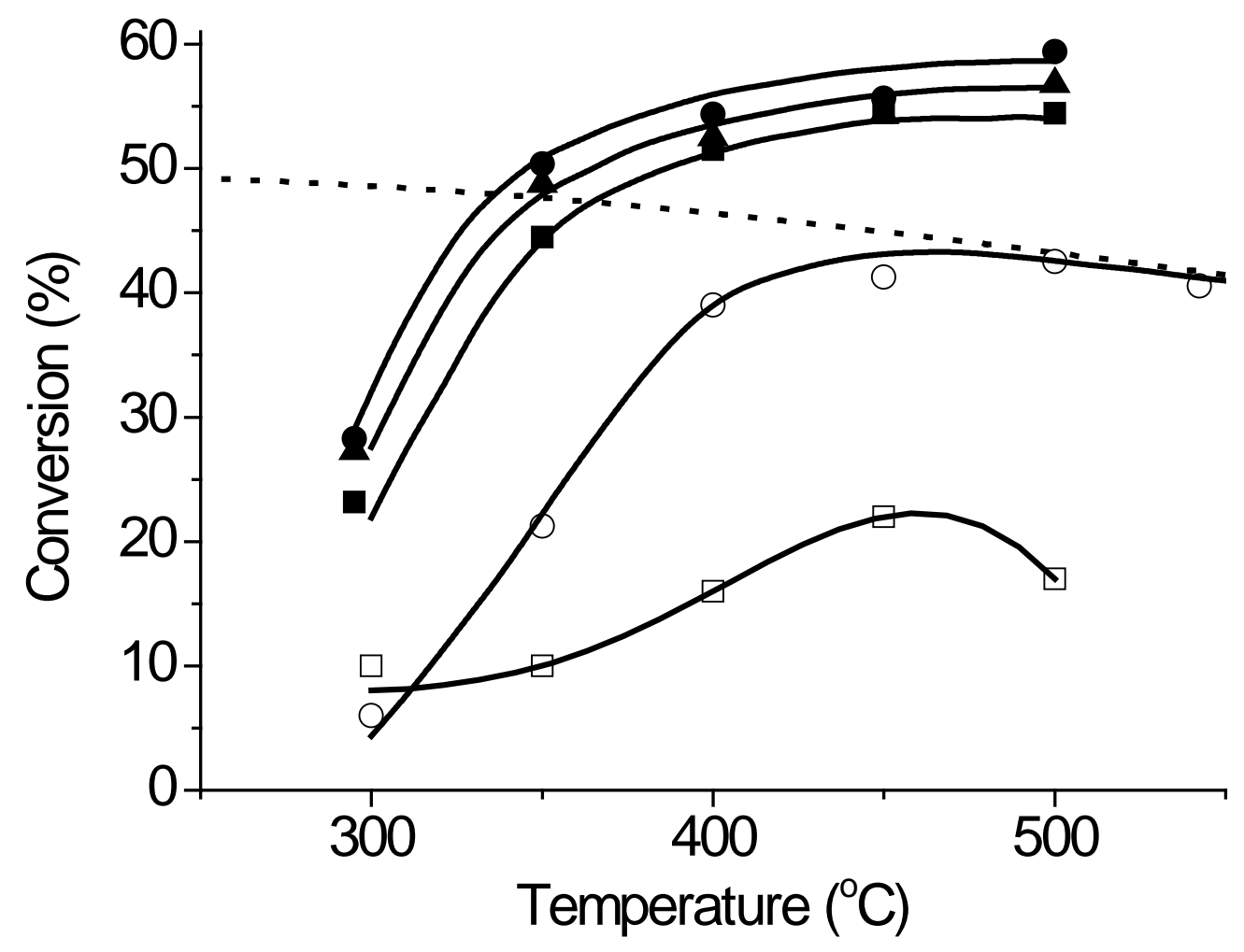

Fig. 9 

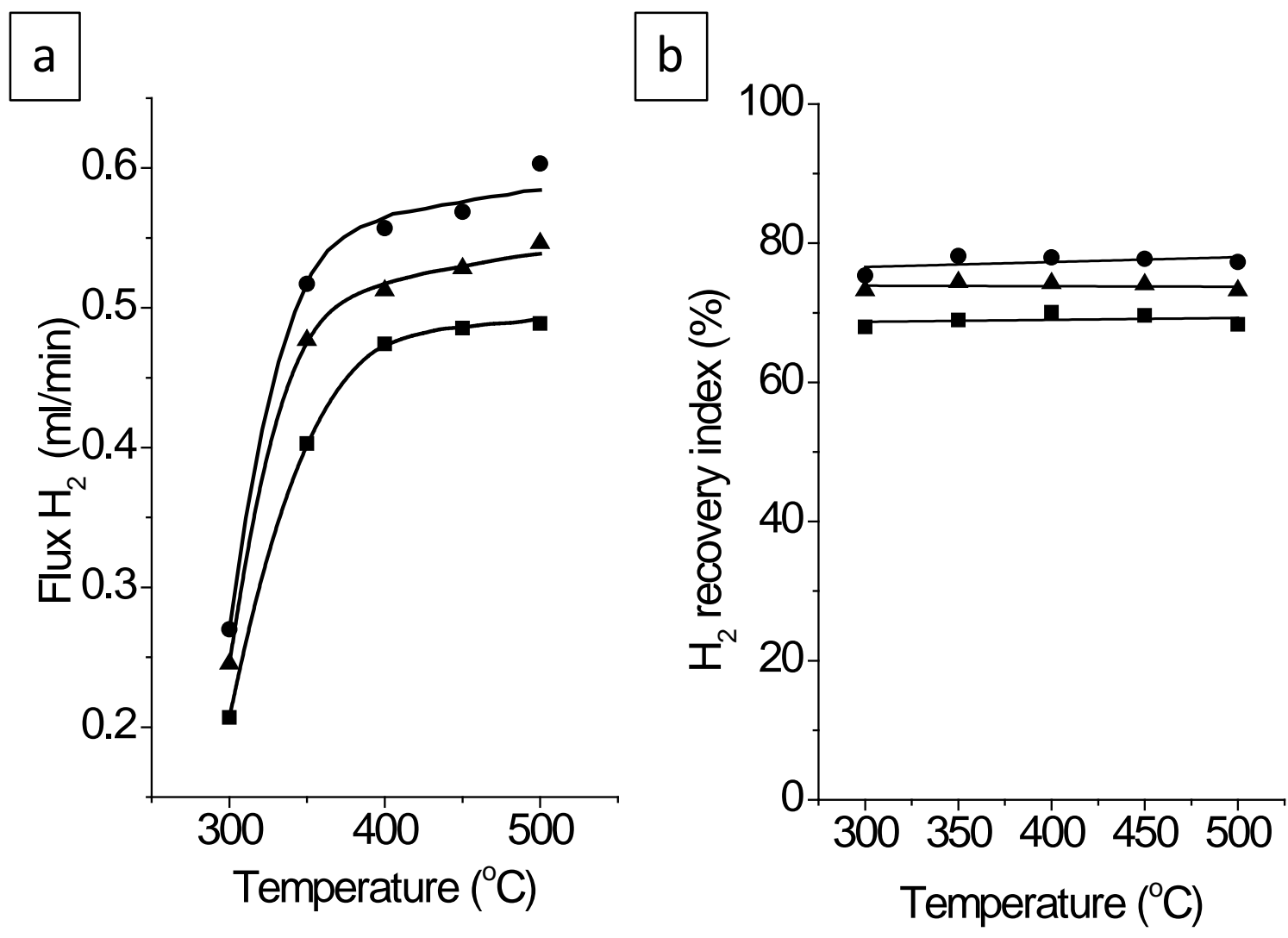

Fig. 10 